\title{
Assessment of a credit scoring system for popular bank savings and credit
}

\author{
Evaluación de un sistema de credit scoring para instituciones \\ de ahorro y crédito popular \\ José Francisco Martínez Sánchez, Gilberto Pérez Lechuga
}

Universidad Autónoma del Estado de Hidalgo, Escuela Superior de Apan, México

Received 4 February 2015; accepted 30 October 2015

Available online 21 January 2016

\begin{abstract}
The current banking system does not meet the needs of financial services, particularly credit to the poorest sectors of society, the banking presence are mainly located in cities and regions with important economic activity, to attend to these excluded sectors have created naturally without supervision and support of the authorities, financial institutions such as credit unions, cooperatives, popular financial companies, among others, called savings banks and loan altogether. However, most of these institutions are not recognized or supervised by the CNBV, which translates into risk for users of services to financial institutions, highlighting the inefficiencies in their lending processes, and decisions to accept or reject a credit application is based on knowledge, experience and judgment of the loan officer. This paper presents the evaluation of a credit scoring system ${ }^{1}$ in terms of cost-efficiency for savings and loan institutions in specific for SOFIPO's and in terms of cost-benefit to the service provider assessment of loan applications. As will be shown in the development of a system work of this nature streamlines the lending process at minimal cost and is a worthwhile investment for the provider of credit scoring services.

All Rights Reserved (C) 2015 Universidad Nacional Autónoma de México, Facultad de Contaduría y Administración. This is an open access item distributed under the Creative Commons CC License BY-NC-ND 4.0.
\end{abstract}

JEL classification: G31; G32; M1; O38

Keywords: ICT; Economic growth; Credit risk

\footnotetext{
E-mail address: marzan67@ @otmail.com (J.F. Martínez Sánchez).

1 The project of credit scoring system includes: analysis of credit process, design and development of system, marketing, training, fine tuning, delivery and service provider.

Peer Review under the responsibility of Universidad Nacional Autónoma de México.
} 


\section{Resumen}

El sistema bancario actual no cubre las necesidades de servicios financieros, y en particular de créditos, a los sectores más desfavorecidos de la sociedad. La presencia bancaria se localiza fundamentalmente en las ciudades y regiones con actividad económica importante, y para atender a estos sectores excluidos se han creado de forma natural, pero sin supervisión ni soporte de la autoridad, entidades financieras como las cajas populares, cooperativas, sociedades financieras populares, entre otras, que en conjunto se denominan entidades de ahorro y crédito popular. Sin embargo, la mayoría de este tipo de instituciones no son reconocidas ni supervisadas por la CNBV, lo cual se traduce en riesgos tanto para los usuarios de los servicios como para las instituciones financieras, destacando las ineficiencias en sus procesos de otorgamiento de créditos, ya que las decisiones de aceptar o no una solicitud de crédito se sustentan en el conocimiento, la experiencia y el criterio del analista de crédito. Este trabajo presenta la evaluación de un sistema de credit scoring, tanto en términos de costo-eficiencia para las entidades de ahorro y crédito, en especial para las SOFIPOS, como en términos de costo-beneficio para el proveedor de los servicios de evaluación de solicitudes de crédito. Como se mostrará en el desarrollo del trabajo, un modelo de esta naturaleza hace más eficiente el proceso crediticio a un costo razonable y es una inversión rentable para el proveedor de servicios de credit scoring. Derechos Reservados ( 2015 Universidad Nacional Autónoma de México, Facultad de Contaduría y Administración. Este es un artículo de acceso abierto distribuido bajo los términos de la Licencia Creative Commons CC BY-NC-ND 4.0.

Códigos JEL: G31; G32; M1; O38

Palabras clave: Tecnologías de Información; Crecimiento económico; Riesgo de crédito

\section{Introduction}

In June 2001 was published in the Official Journal of the Federation the savings-banks law aligned to the best practices in terms of bank credit risk management (Pagos, 2004) in which the figure of Savings and Loan Institutions (EACP), was created and where the following general objectives were envisaged:

(a) To regulate, promote and facilitate the raising of funds or monetary resources and their placement through loans or credits or other operations by popular financial companies, finance companies community, as well as, financial integration rural organizations,

(b) To regulate, promote and facilitate the activities and operations of the popular financial companies, finance companies community and the financial integration rural organizations as well as its healthy and balanced development,

(c) To protect the interests of its customers,

(d) To establish the terms in which the State exercises guidance of the popular financial companies referred in terms of Act.

The Saving and Loan Association Act, see CNBV (2001), seeks to regulate the two most important figures to be taken by (S\&L). These figures are the Cooperative Savings and Loan Societies (S\&L), and the finance companies community (SOFIPO). A SOFIPO is an entity that is part of the Mexican financial system, created to attend the microfinance market, this paper is focused on the SOFIPOs.

A SOFIPO is empowered to receive deposits, loans from banks, public trusts and international organizations, pension funds, insurance and bonding may be issued and operate debit and pre-paid 
cards, loans and credits to the customers, be money transmitter (payment orders and transfers), receive payments for others, make foreign currency at the window for others, distribute insurance, bonds and government resources programs.

The SOFIPOS are subject to supervision by the National Banking and Securities Commission (CNBV), which has all the powers on inspection and monitoring gives applicable Laws. These powers may be exercised directly by the CNBV and auxiliary by the Federations, which are exclusively voluntary grouping of SOFIPOS; and are authorized and supervised by the CNBV. Federations are institutions of public interest, with legal personality and its own non-profit.

In addition, in December 2006, the general provisions applicable to entities were issued applicable to savings banks and loan and integration organizations referred to in The Saving and Loan Association Act, and they set out the requirements that must meet the applications or requests for information formulated by the authorities referred to the Law, in order that the required SOFIPO are in a position to identify, locate and provide news or information requested.

Under this model of operation, institutions responsible and authorized by the CNBV to act as financial agents to raise funds and grant such loans face various challenges to ensure its viability and existence. One of the main challenges faced by this sector is capital, due to these types of entities do not grow because the shareholding base narrows its contributions. And, to leverage the growth of any financial intermediary a higher level of capital is required to generate a significant volume of business and recognition as an alternative savings and credit by society.

Another challenge for strengthening of SOFIPOS against the new economic environment is to have a protection mechanism, since it is essential and relevant so that people who entrust their resources in these vehicles can be certain that there is an institutional effort to protect their savings.

Finally, there is the factor of innovation, this is necessary to achieve greater market penetration, where predominate product launches and really different services, supported by the possibilities offered by technology. The use of tools based on information technology should be seen as an instrument to support SOFIPOS that contributes in achieving their goals and in overcoming the challenges that sets its current operating model.

\section{Approach to the working hypothesis}

It has been hypothesized that a service credit risk valuation supported with credit scoring tools provided by a third and the formation of human capital with high quality standards for operating systems for risk management, are feasible investment in terms of cost-efficiency for EACP and feasible in terms of cost-effectiveness for valuation and consulting service providers.

To test the technical and financial feasibility of the service credit risk valuation for EACP a business plan is elaborated with the following components:

(a) a market analysis to determine the demand for the proposed services,

(b) the marketing policy of the credit service is defined in a schema "on demand" to avoid onerous costs to users,

(c) technical description of the project, detailing the credit scoring algorithm and technology platform that supports credit appraisal services,

(d) finally, the financial projection of the project is done and indicators of cost-efficiency and cost-effectiveness to determine the financial feasibility of the project are calculated, for this purpose the net present value will be used. 


\section{Description of the system and business plan}

The systems used for the assessment of credit processes in the banking financial sector are called credit scoring, according to Hand and Henley (1997), are statistical procedures used to classify those seeking credit, including those who are already customer of the lender in the types for 'good' and 'bad' risk. In the beginning, during the seventies, credit scoring applications were built with statistical techniques (in particular, the discriminant analysis). Subsequently, the methods used evolved into mathematical techniques, econometric and artificial intelligence. In any case, the construction of any application of credit scoring is done by taking customer information contained in the loan applications from domestic sources and even from external sources. The credit scoring estimates at the time it is carrying out the request, what will be the behavior of credit to maturity, considering the risk of the customer is evaluated through a predictive model evaluated of behavior for payment or reimbursement by a score that measures the risk of a borrower and/or of the operation.

\section{Credit scoring definitions}

Credit evaluation is one of the most crucial processes in banks "credit management decisions". This process includes collecting, analyzing and classifying different credit elements and variables to assess the credit decisions. One of the most important tools, to classify a bank's customers, as a part of the credit evaluation process to reduce the current and the expected risk of a customer being bad credit, is credit scoring. Hand and Jacka (1998) stated that "the process (by financial institutions) of modeling creditworthiness is referred to as credit scoring".

Anderson (2007) suggested that to define credit scoring, the term should be broken down into two components, credit and scoring. Firstly, simply the word "credit" means "buy now, pay later". It is derived from the Latin word "credo", which means "I believe" or "I trust in". Secondly, the word "scoring" refers to "the use of a numerical tool to rank order cases according to some real or perceived quality in order to discriminate between them, and ensure objective and consistent decisions". Consequently, credit scoring can be simply defined as "the use of statistical models to transform relevant data into numerical measures that guide credit decisions".

\section{Benefits and criticism of credit scoring}

Benefits of credit scoring: Credit scoring requires less information to make a decision, because credit scoring models have been estimated to include only those variables, which are statistically and/or significantly correlated with repayment performance; whereas judgmental decisions, prima facie, have no statistical significance and thus no variable reduction methods are available (Crook, 1996). Credit scoring models attempt to correct the bias that would result from considering the repayment histories of only accepted applications and not all applications. They do this by assuming how rejected applications would have performed if they had been accepted. An additional essential benefit of credit scoring is that the same data can be analyzed easily and clearly by different credit analysts or statisticians and give the same weights. This is highly unlikely to be so in the case of judgmental methods (Chandler \& Coffman, 1979).

Criticisms of credit scoring: Statistically a credit scoring model is "incomplete", for it leaves out some variables, which taken with the others, might predict that the customer will repay. But unless a credit scoring model has every possible variable in it, normally it will misclassify some people. Another criticism of credit scoring models is the possibility of indirect discrimination 
(Crook, 1996). Furthermore, credit scoring models are not standardized and differ from one market to another; are expensive to buy and subsequently to train credit analysts; and sometimes a credit scoring system may "reject (a) creditworthy applicant because he/she changes address or job" (Al Amari, 2002).

As described above, a service of valuation of credit risk is based on a set of methodologies and statistical tools that must be analyzed is implemented by a multidisciplinary team with specialists in finance, statistics and advanced software developers. Based on their statistical robustness and the ability to use categorical variables, we decided to use credit scoring model.

\section{Services of credit rating are the following}

(a) Based on the information contained in applications for credit and risk analyst knowledge of the socioeconomic background of the applicant, requests are automatically processed through models credit scoring assigning default probabilities and based on some threshold will be classified in "good" or "bad." The previous thing is defined, this is defined in a schema "on demand services", that is, customers (EACP) do not require to have computer systems and databases installed on their infrastructure, but through a WEB environment made the service request and as a result have the classification of the application as "good" or "bad" with their corresponding probability of failure. Thus only pay for services and should not be worrying about the new versions of the computer system either by technological updating or improvements in methods of calculation,

(b) To achieve comprehensive efficient risk management, financial literacy is essential, so escort services and advice to EACP are required to model their business processes aligned to best practices in risk management and regulation in matter. The uncertain and dynamic environment of financial credit markets requires institutions to maintain trained its analysts and decision makers, technical and statistical tools and mathematics that allow modeling environments with these characteristics, so upgrade programs were systematically provide and training consistent with the best practices of risk management and feasible with the characteristics of credit institution's needs.

\section{State of the art in financial services for microfinance institutions}

In rapidly evolving financial markets, applied technologies can be the difference between a larger share of the market or gradual decline. Sustainable microfinance institutions (MFIs) can use technology to increase their scale of operations and offer services to more clients. With costeffective technological solutions that meet their data management needs and match their clients' requirements, these MFIs can cover their operating and financial costs and the risk of loan losses without the need for subsidies.

Microfinance is a business of scale, and, therefore, highly sensitive to variable costs. Even a few centavos of savings per client matter when the MFI is serving tens of thousands of clients with short term loans, savings collection and other financial products. Passing the savings on to clients helps MFIs reach their social objectives. In other words, returns on technology investments that lower operational costs for MFIs can be very high, benefitting tens of thousands of clients.

The fastest way to lower variable costs is to adopt new technologies that speed the analysis of client data, lower transaction costs, and make it easier for clients to use microloans effectively. The key hardware and software needed to apply new technologies to microfinance are already in place, especially point of sale (POS) and mobile phone systems. 


\section{Mobile banking}

The advent of mobile phone payments technologies-whereby users can receive and transfer value in small amounts through the mobile phone network- has the potential to revolutionize access to financial services.

Beyond standard communication services, mobile phones offer four characteristics that directly affect banking transactions: (i) fast message transmission speed; (ii) a high degree of reliability; (iii) low costs; and (iv) security. Whereas only about $25 \%$ of all households in developing countries have formal relationships with banks, more than $40 \%$ are using cellular telephones, and that number continues to grow rapidly.

Mobile banking still faces important challenges, from the perspective of technology development to operator skills and client perceptions. Clients are typically resistant to new technologies, and may be especially reluctant to trust their funds to a wireless system. However, client education efforts can help to overcome such concerns. These operational problems do not limit the potential for a broad microfinance revolution (covering loans, savings, payments and remittances) through mobile phones.

The Philippines financial sector, for example, has been a leader in leveraging mobile phones and networks to deliver cost-effective high-volume, low-value transfer capabilities. Two of the country's mobile network operators offer the functional equivalent of small-scale transaction banking to an estimated 5.5 million customers. ${ }^{2}$ One service provider, Globe Telecom, has partnered with the Rural Bankers Association of the Philippines to offer its "GCash" service, which enables customers to use text messaging to repay loans and make deposits, withdrawals, or transfers from their savings account.

\section{Network systems}

Point-of-sale (POS) terminals are often part of a network that is shared by financial intermediaries; clients from a number of institutions can use the same terminals and agents to make payments. Sharing network infrastructure enables financial institutions to achieve collectively the volume of transactions needed to cover the costs of the software, hardware, and the connectivity required to provide distributed payments services. Some MFIs, particularly in the cooperatives sector, are working together to create economies of scale that enable them to invest in new payments technologies, reducing costs and expanding services to their clients.

\section{Remote data processing}

From Mexico to India, MFIs use mobile devices—-personal digital assistants (PDAs), smart phones and laptops - to analyze a client's risk and determine creditworthiness in the field. These improvements can result in important reductions in paperwork and the time to deliver the loans, and improve client selection. Set-up and operating costs are low, with software development ranging from \$US 20,000 to \$US 80,000. Hardware costs are around \$US 100 per unit, and annual software maintenance contracts are less than \$US 10,000.

The evaluation and approval of a credit application, for example, requires detailed information on the client, the business, family and other relevant aspects of the operation. Using a mobile device, the loan officer can enter information directly into the system and reduce the number of errors or incomplete applications. Optimally, loan officers can also access all prior information

\footnotetext{
277 CGAP 2008. Regulating Transformational Branchless Banking: Mobile Phones and Other Technology to Increase Access to Finance, Focus Note 43.
} 
on a client, and run credit scoring programs on existing clients with new loans and on new clients-oftentimes generating a credit decision on the spot.

One of the early adopters of PDA technology for microfinance applications was Compartamos, a specialized microfinance provider using village banking for women clients in Mexico. Compartamos found that PDAs raised loan officer efficiency and data access in the field. ${ }^{3}$ The example of Compartamos, however, reveals a potential problem with early adoption of new technology. That is, the efficiency of using PDAs can only be sustained if the overall management information system (MIS) is stable, permits high-speed data transfer between branches for consolidation, and has ongoing technical support. The Compartamos example also suggests that PDAs require mature loan products, to avoid constant adjustments as loan specifications and data requirements change over time.

Managing a successful technology implementation program requires careful planning and attention to many factors. Management will need to determine the specific objectives of a technology project, assess the variables that will drive costs and benefits, and evaluate before deciding to adopt new information and communications technology, the MFI should examine its goals and evaluate the state and use of its existing systems. If the management expects to reengineer the entire system, a phased approach is usually best. Innovative solutions for loan processing and payments distribution, for instance, require a robust management information system.

\section{The potential of digital data}

A global scan by CGAP found at least 36 new start-up companies or products focused on harnessing digital data for financial services (Consultative Group to Assist the Poor, 2015). While many of these models are in trial phases, they signal opportunities to advance financial inclusion. One opportunity is exploring the possibility of assessing credit risk of people for whom no information or formal records exist, allowing many to establish a formal credit history and to eventually engage more broadly with formal financial service providers (FSPs). Potential benefits for providers could be substantial: lowering costs and reaching many new clients. For clients, digital data use can reduce time and documentation burdens, making services more accessible to a larger number of clients otherwise excluded.

Advanced analytics make digital data even more useable not only are the sources and volumes of data rising, but the ability to use data is also advancing. A key enabler of this is the ease of accessing large amounts of information over the internet. Data are increasingly stored in formats that are easier to read by computers (machine readable) and stored where they can be easily accessed by multiple users (in the "cloud"). Data no longer need to come neatly in rows and columns. New database management software makes it possible to derive insights from datasets that would earlier have been too large or too varied to compare. ${ }^{4}$

The earliest evidence comes from experiments with credit. ${ }^{5}$ Several firms (e.g., Cignifi, First Access, and Tiaxa) specialize in credit analytics using new digital data sources; especially mobile operator call data records (CDRs). ${ }^{6}$

\footnotetext{
${ }^{3}$ CGAP IT Innovation Series-Personal Digital Assistants. Charles Waterfield, CGAP, 2004.

${ }^{4}$ For example, Big Data often cited as new analytics software for large data sets.

${ }^{5}$ An initial scoping by Dahlberg for CGAP found that more than half of new data-focused start-up businesses are for credit.

${ }^{6}$ CDRs are records of each call or text that notes the time, length, phone numbers involved, and other data. These records are kept primarily for billing the customer for usage. Mobile operators also can collect location data, purchases of airtime, and in some instances also mobile payments usage.
} 
Early experimentation with digital data predominantly involves credit products. But there are wider use cases. We would expect future uses to fall into one of the three broad uses across the customer engagement cycle.

(a) Finding new customers,

(b) Deepening customer relationships,

(c) Managing risks.

For the use of digital data to achieve its potential it must do more than transform provider business models and contribute to major advancements to bring valued services to those excluded from formal financial services. The most basic measure of some success will be including those who were previously excluded. Poor clients may also benefit by having to present less documentation and to incur less time to access services.

Today the financial sector in Mexico has available applications to operate their lending processes, it has systems with high standards of performance and safety, and we can say that is the most advantaged sector in the use and development of information technology; however a high percentage of the technology used are adaptations of models designed for global financial institutions and not always suited to the reality of the Mexican financial sector, especially in MFI's that are not banks or brokerage firms, such as, popular financial companies, finance companies community; as well as, Financial Integration of Agriculture and PYMES, among others; which do not have the budgetary resources or specialized human resources to operate complex systems of risk management, hence the rationale for developing an information system, as the one proposed, to support the EACP in decision making during the evaluation of credit and does not imply lavish expenditures, if not to pay for services required "on demand".

So far no information is available on the market a product with these features, however extensive this type of services demand is expected, demand will be discussed in detail in the next section.

\section{Market study}

According to information provided by the CNBV through its website, 44 SOFIPOS authorized by the CNBV with assets of 20 billion 318 million pesos and a portfolio of 2.7 million guests currently exist, of which $60 \%$ are enterprise customers "Libertad", $11 \%$ "Microemprededor" and $6 \%$ "Fincomun". These data show a high market concentration in these three institutions approved, however, there are institutions within the savings and loan industry that are in the process of authorization or operating independently of the monitoring and supervision of the CNBV.

The Mexican Association of SOFIPOS (AMSOFIPO) argues that on average, the sector, integrated to date by 44 entities of this nature duly authorized, has grown in number of customers (credit and savings) $21 \%$ per annum. Highlight it has also increased the number of banks in operation, with an average of $13 \%$ annually over the last three years, and branches in $26 \%$ per annum, which is expected to exceed 1200 branches at the end of 2013, distributed throughout country.

From 2010 an estimated $18 \%$ annual growth was observed in the loan portfolio in the sector which is expected to reach 20,000 million pesos at the end of 2013, while the bank obtained a $13 \%$ increase in this indicator in the last year. If we consider average loans of $4000^{7}$ pesos in

\footnotetext{
${ }^{7}$ Information obtained from the BID publication "Microfinance in Latin America and the Caribbean: the sector in figures 2011", published in October 2011 (BID, 2011).
} 
such institutions, to 2013 at least 5 million credit applications would be evaluated, regardless of rejected applications, estimating $40 \%$ of rejected requests regarding authorized, we would have an estimated total of 7 million credit applications that would be analyzed by the credit bureaus for potential authorization.

If the $18 \%$ growth is kept in the loan portfolio of the sector, for the next two years would have approximately 1.2 million annual credit applications which would involve considerable departments credit analysis efforts, so that having an automated credit assessment process will help analysts and executives make decisions more efficiently.

Initially customers for the assessment service proposed is 44 SOFIPOS authorized by the $\mathrm{CNBV}$, although it is also required for those who are in the process of authorization or operating independently of monitoring. Until July 2011 the Ministry of Economy through National Fund for the Support of Social Enterprises (FONAES) had a census of 907 solidarity funds across the country, of which 453 are authorized by the CNBV and 454 in the registration process, this universe of institutions are also potential customers for evaluation services of credit applications, since they will be founded with fiscal resources, under the rules of the Financial Reform approved in November 2013. Therefore, it is estimated that the loan portfolio of MFI's (SOFIPOS, SOFOMES, SOCAPS, charity funds, etc.) would grow at the rate of 20 or $25 \%$ a year from 2015 .

Regarding to analysis products credit scoring in the field of microfinance is virtually zero in some cases (institutions level $\mathrm{IV}^{8}$ ) use systems designed for the banking sector and other institutions (levels I, II and III) the evaluation of credit applications occur discretionary opinion by analysts and managers in the areas of credit.

The conformation of the field of micro-finance in Mexico has the genesis to cover a market excluded by the banking sector, so its development is positioned by geographic regions and productive sectors, generating growth unrelated to the supervision and authorization of the competent authority and with high risks for both banks and savers and investors.

Therefore the following initial barriers to a project are identified with these features:

(a) The institutions do not have documented processes,

(b) Limited financial culture,

(c) Unstructured information repositories,

(d) There is no incentive to share information, that is, there is no central information on the credit performance of borrowers nor microfinance,

(e) Institutions focused on clients of a single sector,

(f) There is no internal controls,

(g) Corporate governance nonexistent,

(h) No guarantee schemes,

(i) No willingness to change,

(j) Non-automated processes,

(k) Family Business,

(l) Impairment by the regulatory authority.

\footnotetext{
${ }^{8}$ Operations level I: Popular financial companies in the amount of total assets less than or equal to 15 million UDIS. Operations level II: Popular financial companies in the amount of total assets exceeding 15 million and less than or equal to 50 million UDIS. Operations level III: Popular financial companies in the amount of total assets exceeding 50 million and less than or equal to 280 million UDIS. Operations level IV: Popular financial companies in the amount of total assets exceeding 280 million UDIS.
} 
In November 2013 the legislature passed the financial reform, which considers actions that will encourage increased lending to the micro-credit sector, particularly in the popular financial sector reform aims to increase the services provided in correspondent banking scheme, which would be able to obtain greater economic benefits through commissions, but also greater exposure to various risks. This strengthens the proposed credit risk system as proposed herein.

\section{Project description (business approach)}

The critical success factor for the project is financial literacy, therefore, it is necessary to conduct a dissemination strategy and support for popular savings and credit through organizing seminars, talks and meetings with stakeholders, to emphasize and convince about the benefits of having risk management models such as that proposed in this paper.

\section{Sales policy}

(a) In the case of application credit evaluation service with credit scoring tools through applications in WEB environment, are services "On demand" and costs will depend on the monthly volume and hours of service,

(b) In relation to the support and advice will be quoted per hour and the cost will depend on the required level of expert or expertise required,

(c) Finally service training and refresher short courses will be organized in one to two weeks and courses to be taught with the support of an academic institution recognized top level, the costs will depend on the length and subject matter to develop.

\section{Promotion and advertising formulae}

Besides disseminating the project in print and electronic media, the following actions will be implemented:

a) Participation in exhibitions of the microcredit sector and popular savings organized by government agencies and financial institutions, national and international associations.

b) Creating a web page for customers with relevant information and services "chats" to attend questions and comments.

c) Building applications for mobile devices with a "beta" version of the product

d) Creating an academic version for use in higher education institutions

e) Creating a virtual online lab to make analysis risk simulations in the financial sector

The financial sector is dynamic, tools and risk management models are also developed in this logic, therefore, another advantage of the proposed service model "On demand" is that updates either technological change or improvements in the tools of calculating credit scoring is completely transparent to the client, "On demand" is that updates either technological change or improvements in the tools of calculating credit scoring is completely transparent to the customer, that is, whenever there is any change, we will notify the customer and if the he agrees, he will automatically have available at no extra cost improvements or upgrades without making changes to their systems or infrastructure. 


\section{Technical description of the project}

\section{Credit scoring calculation}

To propose a model whose response or dependent variable is binary - since the two scenarios is that the customer pays (0) or the customer does not pay (1) - a model of binary logistic regression was applied in order to avoid disadvantages of linear regression models or discriminant analysis. Within credit scoring parametric techniques, ${ }^{9}$ binary logistic regression was chosen as the statistical technique employed due to its attractive features, among which are the following see Rayo and Lara (2010) and Hussein (2011).

(a) The statistical properties are more suitable than linear models in which sometimes inefficient estimators are obtained,

(b) Due to the characteristics of the credit history of the SOFIPOS where qualitative information to supplement the shortage of quantitative variables, binary logistic regression supports categorical variables with more flexibility than the linear models,

(c) Allows estimating the probability of credit default according to the values of the independent variables,

(d) Determine the influence of each independent variable on the dependent variable (paid or unpaid) as the OR (odd ratio or advantage). This is defined as $\exp (\beta)$, where exp is the base of natural logarithms (a constant whose value is 2.718 ), and $\beta$ is the regression parameter value of the independent variable in the model. An OR greater than 1 indicates an increase in the probability of the event of default on the fact pay when the explanatory variable increases by one unit; conversely, a lower OR than 1 indicates the opposite.

\section{The binary logistic regression model}

The first difference between normal regression, and logistic regression is the use of a dichotomous dependent random variable. This type of variable is called a Bernoulli variable. The use of normal linear regression for this type of dependent variable would violate several of the assumptions. The following are also reasons why linear regression cannot be used:

(a) If one uses linear regression, the predicted values will become greater than one or less than zero, if moved far enough on the $x$-axis. This values are theoretically inadmissible,

(b) Another assumption that is violated is that of constant variance of the dependent variable across the independent variables. If the dependent variable is binary, the variance is $p q$. Now, if $50 \%$ of the observed sample has 1 as dependent variable, the variance is at its maximum of $p q=0.25$ as one moves to the extremes, the variance decreases. If $p=0.1$, the variance is $(0.1)(0.9)=0.09$ so as $p$ approaches 0 or 1 , the variances approaches zero,

(c) The significance test of the parameters rest upon the assumption that the errors of the prediction (residuals) are normally distributed. As the dependent variable takes the values of 1 and 0 only, this assumption is very hard to justify, even just approximately.

\footnotetext{
${ }^{9}$ Credit scoring parametric techniques uses a distribution function or known classification, as they estimate some parameters to explain a particular event, so that they would be aligned to the observations of a sample. These techniques are very useful when the set of variables follow a given distribution.
} 
Table 1

Analysis failure of the credit card customers.

\begin{tabular}{lrrr}
\hline Family size & \multicolumn{2}{c}{ Failure indicator } & Rate \\
\cline { 2 - 4 } & 0 & 1 & 0.100 \\
\hline 1 & 9 & 1 & 0.133 \\
2 & 13 & 2 & 0.250 \\
3 & 9 & 3 & 0.333 \\
4 & 10 & 5 & 0.461 \\
5 & 7 & 6 & 0.625 \\
6 & 3 & 5 & 0.764 \\
7 & 4 & 13 & 0.800 \\
\hline
\end{tabular}

Source: Own formulation.

In linear regression models assume that the conditional mean of the dependent variable, given the independent variable $x$, can be expressed as a linear equation in $x$,

$$
E(y \mid x)=\beta_{0}+\beta_{1} x .
$$

This expression implies that when $x$ takes values between $(-\infty, \infty)$

$$
0 \leq E(y \mid x) \leq 1
$$

To establish a bound on the conditional mean, suppose the defaults by customers on credit cards is analyzed, for which is included as an independent variable the size of families and taken the proportion of default for each family size as shown in Table 1.

Fig. 1 shows that the probability of default gradually approaches one as the family size increases. Such curve has the shape of an "S" and is called logistic curve which is determined by the following equation:

$$
p=\pi(x)=\frac{e^{\beta_{0}+\beta_{1} x}}{1+e^{\beta_{0}+\beta_{1} x^{\prime}}}
$$

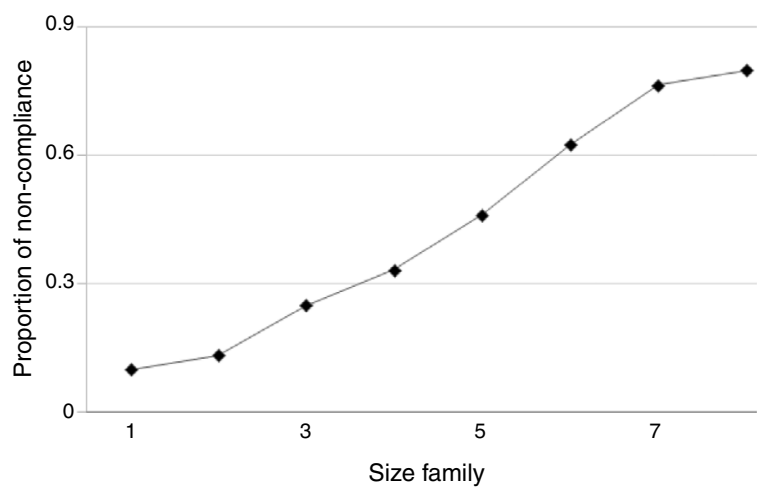

Fig. 1. Probability of default of credit card customers. Source: Own formulation. 
where $\pi(x)$ is $E(y \mid x)$, i.e., the probability of default. Reassigning terms, we have

$$
\frac{\pi(x)}{1-\pi(x)}=e^{\beta_{0}+\beta_{1} x}
$$

besides,

$$
\begin{aligned}
& \ln \left(\frac{\pi(x)}{1-\pi(x)}\right)=\beta_{0}+\beta_{1} x, \\
& G(x)=\ln \left(\frac{\pi(x)}{1-\pi(x)}\right)=\beta_{0}+\beta_{1} x .
\end{aligned}
$$

$G(x)$ is called the logistic transformation which has many of the desirable properties of a linear regression model; is linear in its parameters can be continuous and take values between $(-\infty, \infty)$ depending on the domain of $x$.

In a linear regression model assumes that the dependent variable can be expressed as $y=$ $\beta_{0}+\beta_{1} x+\varepsilon$. Where $\varepsilon$ is distributed with zero mean and constant variance. Considering the binary dependent variable given as the value of $x$, now expressed as $y=\pi(x)+\varepsilon$. The errors $\varepsilon$ has two possible values, if $y=1$, then $\varepsilon=1-\pi(x)$ with probability $\pi(x)$, if $y=0$, then $\varepsilon=-\pi(x)$ with probability $1-\pi(x)$. Thus, $\varepsilon$ is distributed with zero mean and variance $\frac{\pi(x)}{1-\pi(x)}$. Therefore as the error term is distributed in this way, we have that the conditional distribution of the dependent variable is a binomial distribution with a conditional mean given by the conditional mean $\pi(x)$.

To fit a logistic regression model $p=\pi(x)=\frac{e^{\beta_{0}+\beta_{1} x}}{1+e^{\beta_{0}+\beta_{1 x^{\prime}}}}$, a set of data is required to estimate the values for the unknown parameters $\beta_{0}$ and $\beta_{1}$, so as to minimize the square of the sum of the errors (SSE). With some models such as logistic regression there is no mathematical solution which yields an explicit expression for the parameter estimation by ordinary least squares. The method we will use is the Maximum Likelihood, which produces values for the unknown parameters that maximize the probability that they are obtained from the observed data.

If $y$ takes values of 0 or 1 , the expression for $p=\pi(x)=\frac{e^{\beta_{0}+\beta_{1} x}}{1+e^{\beta_{0}+\beta_{1} x^{\prime}}}$ gives the conditional probability that $y=1$ given $x, P(y=1 \mid x)$. It follows that $1-\pi\left(x_{i}\right)$ is $P(y=0 \mid x)$ for a comment $\left(x_{i}, y_{i}\right)$ where $y_{i}=1$, the contribution to the likelihood function is $1-\pi\left(x_{i}\right)$ and can be expressed as:

$$
\pi\left(x_{i}\right)^{y_{i}}\left[1-\pi\left(x_{i}\right)\right]^{1-y_{i}}
$$

where observations are independent, so the likelihood function is obtained by the product of the terms given in the above expression.

$$
L(\beta)=\ln \left(l(\beta)=\sum_{i=1}^{n}\left\{y_{i} \ln \left[\pi\left(x_{i}\right)\right]+\left(1-y_{i}\right) \ln \left[1-\pi\left(x_{i}\right)\right]\right\} .\right.
$$

In logistic regression, minimizing the log-likelihood function generates equations that are not linear in the parameters, then numerical methods are used to approximate the solution. In the example of default credit card, the chances of default size for a family of 8 are obtained as follows:

$$
\begin{aligned}
\text { Odds } & =\frac{p}{1-p} \\
& =\frac{0.8}{0.2}=2
\end{aligned}
$$


It means the ratio is 4 to 1 . Now the logistic transformation is used for logistic regression. This is precisely, the natural logarithm of the possibilities of default.

$$
\begin{aligned}
& G(x)=\ln \left(\frac{\pi(x)}{1-\pi(x)}\right)=\beta_{0}+\beta_{1} x . \\
& G(x)=\ln (\text { Odds }) \\
& \ln \left(\frac{\pi(x)}{1-\pi(x)}\right)=\beta_{0}+\beta_{1} x, \\
& \ln \left(\frac{p}{1-p}\right)=\beta_{0}+\beta_{1} x, \\
& \frac{p}{1-p}=e^{\beta_{0}+\beta_{1} x}, \\
& p=\pi(x)=\frac{e^{\beta_{0}+\beta_{1} x}}{1+e^{\beta_{0}+\beta_{1} x^{\prime}}}
\end{aligned}
$$

The central process models credit scoring will be hosted on a high availability server and safe communication channels. Also, if the client requires centralized databases will be taken to protect the information of their applications under the privacy standards established by the competent authority, ensuring the availability, confidentiality and integrity of their information. Having information in a single database will allow institutions to reach sector information which will comply with the information provided by all EACP and subscribe an inter-institutional collaboration, this may help correct credit market failures in the popular sector associated with asymmetric information.

Initially the demand for services does not require major investments to housing credit scoring process, however, according to the expected demand for the 2016 project, which is estimated at 10-20\% of market supply, should be considered an investment for the purchase or rental of the edge technology infrastructure to ensure adequate care of the volume of requests for credit evaluation of various EACP.

\section{Conceptual framework of the technological architecture}

The purpose of this and next section is to provide a comprehensive overview of the general architecture of the information system proposed, using different views of the architecture to illustrate different aspects of the system, the notes in this section are based basically on Hussain (2014).

The client-server model in a distributed computing system

A distributed computing system is a set of application and system programs, and data dispersed across a number of independent personal computers connected by a communication network. In order to provide requested services to users the system and relevant application programs must be executed. Because services are provided as a result of executing programs on a number of computers with data stored on one or more locations, the whole computing activity is called distributed computing. 
A natural model of distributed computing is the client-server model, which is able to deal with the problems generated by distribution, could be used to describe computation processes and their behavior when providing services to users, and allows design of system and application software for distributed computing systems. According to this model there are two processes, the client, which requests a service from another process, and the server, which is the service provider. The server performs the requested service and sends back a response. This response could be a processing result, a confirmation of completion of the requested operation or even a notice about a failure of an operation.

The most important features of the client-server model are simplicity, modularity, extensibility and flexibility. Simplicity manifests itself by closely matching the flow of data with the control flow. Modularity is achieved by organizing and integrating a group of computer operations into a separate service. Also any set of data with operations on this data can be organized as a separate service. The whole distributed computing system developed based on the client-server model can be easily extended by adding new services in the form of new servers. The servers which do not satisfy user requirements can be easily modified or even removed. Only the interfaces between the clients and servers must be maintained.

\section{There are three major problems of the client-server model}

The first is due to the fact that the control of individual resources is centralized in a single server. This means that if the computer supporting a server fails, then that element of control fails. Such a solution is not tolerable if a control function of a server is critical to the operation of the system (e.g., a name server, a file server, an authentication server). Thus, the reliability and availability of an operation depending on multiple servers is a product of reliability of all computers and devices, and communication lines.

The second problem is that each single server is a potential bottleneck. The problem is exacerbated as more computers with potential clients are added to the system.

The third problem arises when multiple implementations of similar functions are used to improve the performance of a client-server based system because of a need to maintain consistency. Furthermore, this increases the total costs of a distributed computing system.

\section{Cooperation between clients and servers}

In a distributed computing system there are two different types of cooperation between clients and servers. The first type assumes that a client requests a temporary service. The second one is generated by a client that wants to arrange a number of calls to be directed to a particular serving process. This implies a need for establishing long term bindings between this client and a server. A service provided to the user by a distributed computing system based on the client-server model could require a chain of cooperating servers.

A distributed computing system has the following functions:

(a) Improve performance through parallel execution of programs on a cluster (sometimes called network) of workstations,

(b) Decrease response time of databases through data replication,

(c) Support synchronous distant meetings,

(d) Support cooperative workgroups, and

(e) Increase reliability by service multiplication, etc. 
To perform these functions, many servers must contribute to the overall application. This implies a need to invoke multiple services. Furthermore, it would require in some cases simultaneous requests to be sent to a number of servers. Different applications will require different semantics for the cooperation between clients and servers, as illustrated in the following paragraphs.

\section{Cooperation in the systems supporting parallel execution}

In a distributed computing system supporting parallel execution, there are some parts of a program which could be executed as individual processes on separate computers. For this purpose a process (parent), which coordinates such parallel processing of individual processes (children), causes them to execute on selected idle computers and waits for computational results. In this case the parent process acts as a client and the child processes as servers, in a one-tomany communication pattern. However, the parent process cannot proceed any further unless all children send back responses.

\section{Cooperation in the systems supporting a distributed database}

Similar semantics of cooperation between a client and multiple servers in a distributed computing system occur in supporting a distributed database. To commit a transaction all operations performed on a set of databases must be completed successfully. Thus, a client process which executes a transaction sends operation requests to relevant databases (servers) and waits for the results of the operations. The client process can be involved in other operations, however, responses from all database servers must be received to commit the transaction.

\section{Client-server interoperability}

Reusability of servers is a critical issue for both users and software manufacture due to the high cost of software writing. This issue could be easily resolved in a homogeneous environment because accessing mechanisms of clients may be made compatible with software interfaces, with static compatibility specified by types and dynamic compatibility by protocols.

Cooperation between heterogeneous clients and servers is much more difficult as they are not fully compatible. Thus, the issue is how to make them interoperable. Wegner (1996) defines interoperability as the ability of two or more software components to cooperate despite differences in language, interface, and execution platform.

There are two aspects of client-server interoperability: a unit of interoperation, and interoperation mechanisms. The basic unit of interoperation is a procedure (Wegner, 1996). However, larger-granularity units of interoperation may be required by software components. Furthermore, preservation of temporal and functional properties may also be required.

There are two major mechanisms for interoperation:

Interface standardization: The objective of this mechanism is to map client and server interfaces to a common representation. The advantages of this mechanism are: (i) it separates communication models of clients from those of servers, and (ii) it provides scalability, since it only requires $m+n$ mappings, where $m$ and $n$ are the number of clients and servers, respectively. The disadvantage of this mechanism is that it is closed.

Interface bridging: The objective of this mechanism is to provide a two-way mapping between a client and a server. The advantages of this mechanism are: (i) openness, and 


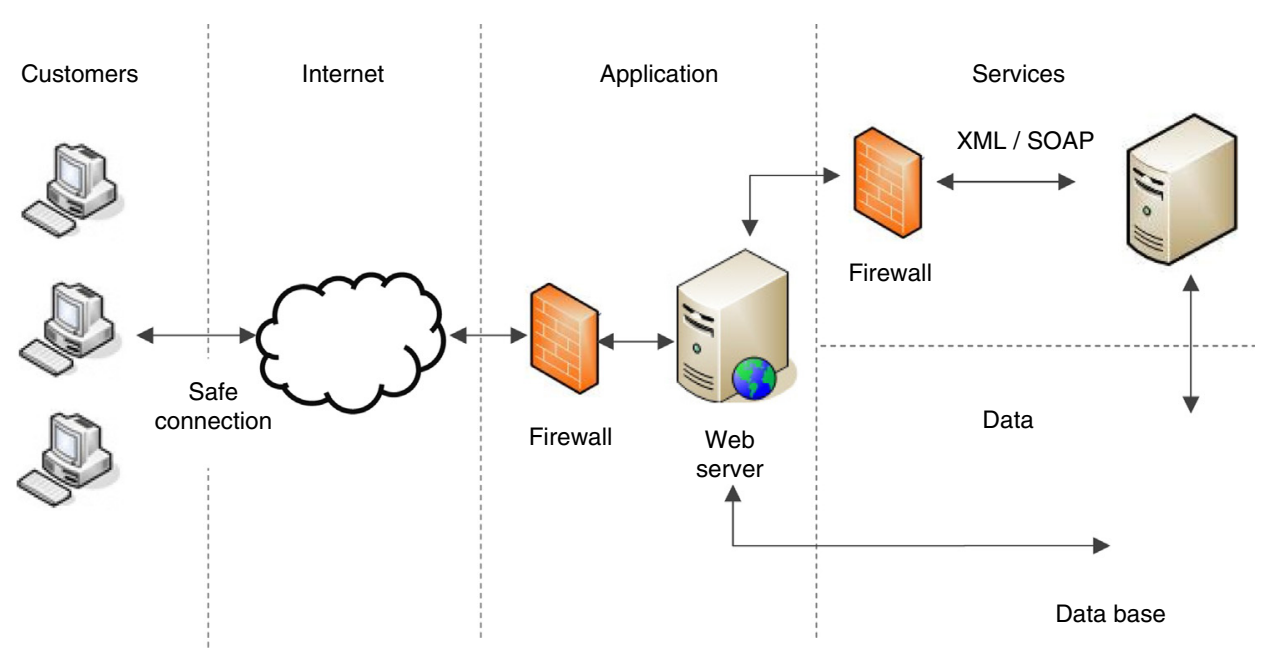

Fig. 2. General representation of the proposed architecture. Source: Own formulation.

(ii) flexibility - it can be tailored to the requirements of a given client and server pair. However, this mechanism does not scale as well as the interface standardization mechanism, as it requires $m^{*} n$ mappings.

\section{General representation of the proposed architecture}

Within the proposed information system provides a model is contemplated a model of distributed client-server application type, in which different client computers can access to the application via the Internet.

The data generated and consumed by the proposed system are stored in another computer equipment named Server database which have access only the Web Server and the Server Service (which is discussed below), making impossible direct interaction to ensure data privacy and integrity.

As mentioned above so far the implementation of the logistic regression technique, defined as a service that classifies a credit application entered as "good" or "bad" with its corresponding failure probability is expected. Subsequently is intended to be incorporated in a second version of the computer system, classification services based on more efficient techniques such as Bayesian Networks or Genetic Algorithms. Because of this and in order to provide scalability to the proposed system, each credit scoring services provided by the system will reside on another server that will have restricted access and whose operation is based on the use of Web Services through standard XML/SOAP. Fig. 2 shows a representation of the proposed architecture.

The main advantages of using this architecture are:

(a) Centralized control of resources, data and access,

(b) Ease of maintenance and updating the server side: This is because the server side can maintain or upgrade easily. For example, an update is applied to a single server, but the benefits are reaped by multiple clients usually no need for them to upgrade anything, 
(c) All information is stored on the server side, which tends to have higher security than customers,

(d) Interoperability between software applications regardless of their properties or the platforms on which they are installed.

\section{Security of the proposed architecture}

It aims to provide with different levels of security to the system proposed through the following:

(a) To provide an income through a secure system model and passwords,

(b) Installation of a programming routine that performs the functions of input filter to web server communication to avoid semantic attacks, routines and cross forged HTTP requests,

(c) Setting up a hardware and software FIREWALL to enable communication only to authorized computers connected in networks,

(d) Use of safety certificates for the consumption of credit scoring services.

\section{Deployment view}

The implementation view will follow the design pattern MVC (Model-View-Controller). This pattern raises the separation of the problem into three layers: the model layer, controller layer and the view layer as it is shown in Fig. 3.

(a) The model is the representation of information with which the system operates, therefore manages all access to this information, both queries and updates. Send the 'view' that part of the information at any time is asked to be shown. Requests for access or manipulation of information reaching the 'model' through the 'driver',

(b) The Controller responds to user actions and invokes requests to 'model' when a request for information is made. It can be said that the 'driver' is the intermediary between the 'view' and 'model',

(c) The view shows the 'model' in a format suitable for interacting, therefore, requires from this 'model' the information that must be represent as an output.

\section{Process view}

In this view is shown the process in which the system is based through the set of logically related tasks with the objective of assessing the application for microcredit. The proposed process is shown by taking into account three levels of granularity as shown in Fig. 4.

\section{Project management}

\section{Project scope}

In this section some international practices for project management are provided, which guarantee the fulfillment of the objectives and goals of a project.

The project includes:

(a) Designing and developing computer software to identify, measure and quantify credit risks that savings and loans institutions face, 
(b) Building human capital with high quality standards for operating systems for risk management.

The project DOES NOT include:

(a) It is assumed that the SOFIPOS customers have the technological infrastructure to access the Internet and view the system. The project does not include any equipment, manning, training, etc. in infrastructure,

(b) The project does not include the capture, formatting, generation or any manipulation of historical information relating to the operations and approved and rejected transactions for each customer.

\section{Project planning}

Based on the current situation; is proposed to form an interdisciplinary team with experience in similar projects that add value for their knowledge of processes and technology. They, together

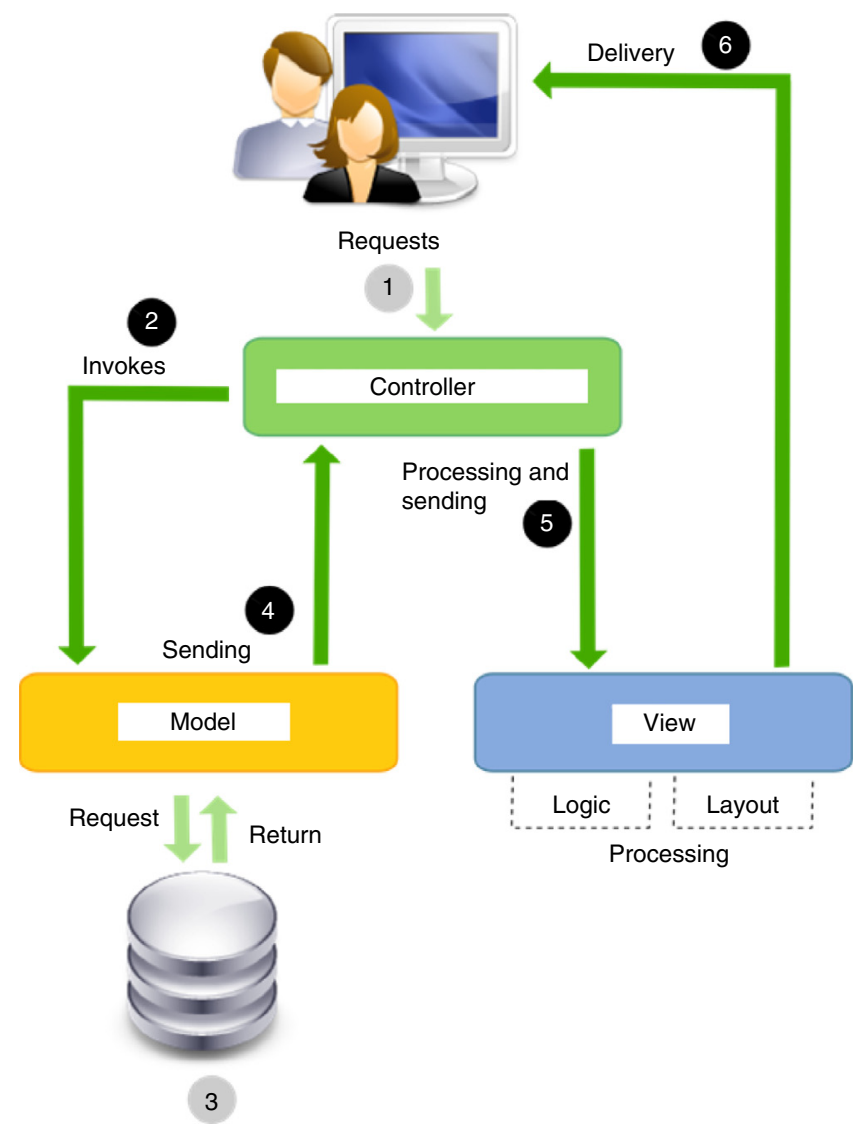

Fig. 3. Implementation view. Source: Own formulation. 


\section{First level}

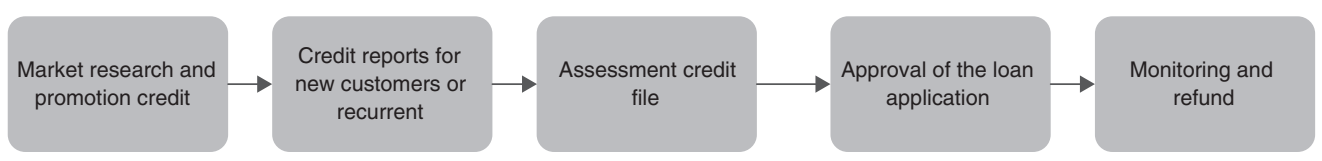

Second level
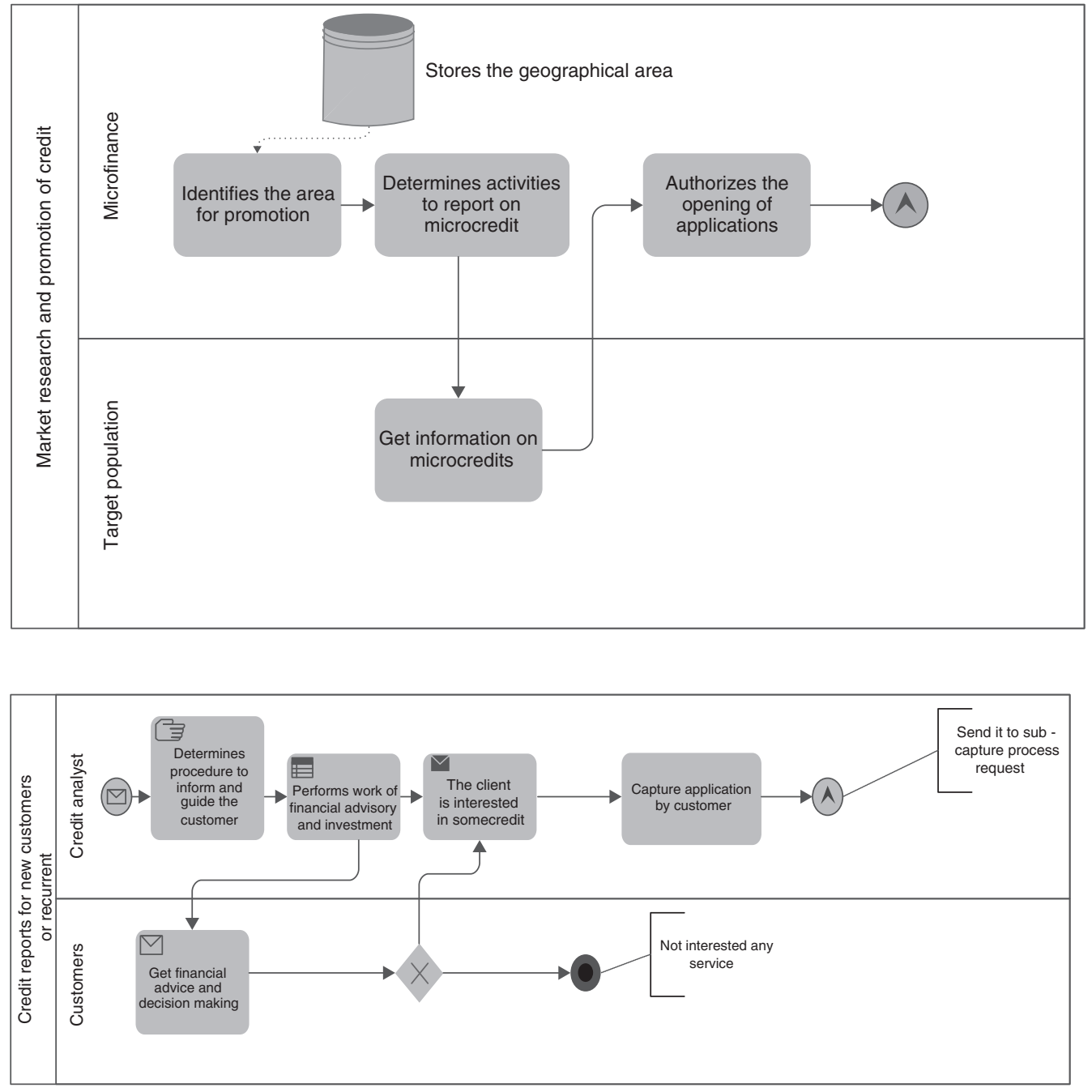

Fig. 4. Model lending processes.

Source: Own formulation. 


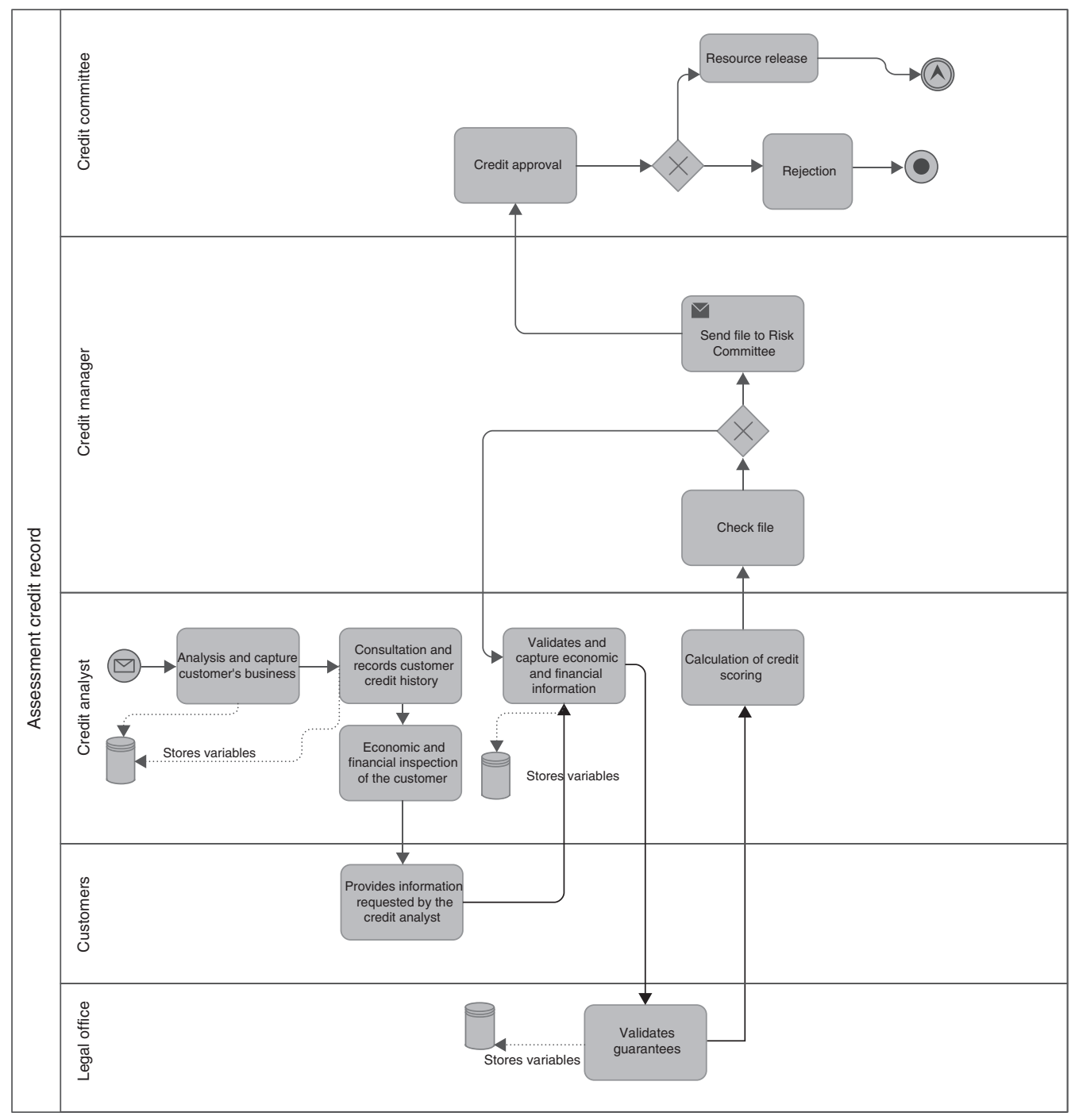

Fig. 4. (Continued)

with the key players of the EACP must identify, analyze and choose the best solution that gives value to the operation of EACP.

Much of the success of this implementation depends on the definition and analysis process obtained as part of the initial diagnosis. This is why it is required of the key players are fully aware of management control and operation of the area.

Considering the above, project planning including the methodology used, the definition of developmental stages the detailed allocation of activities and responsibilities, defining roles, control mechanisms, among others; the project will be detailed when starting. 


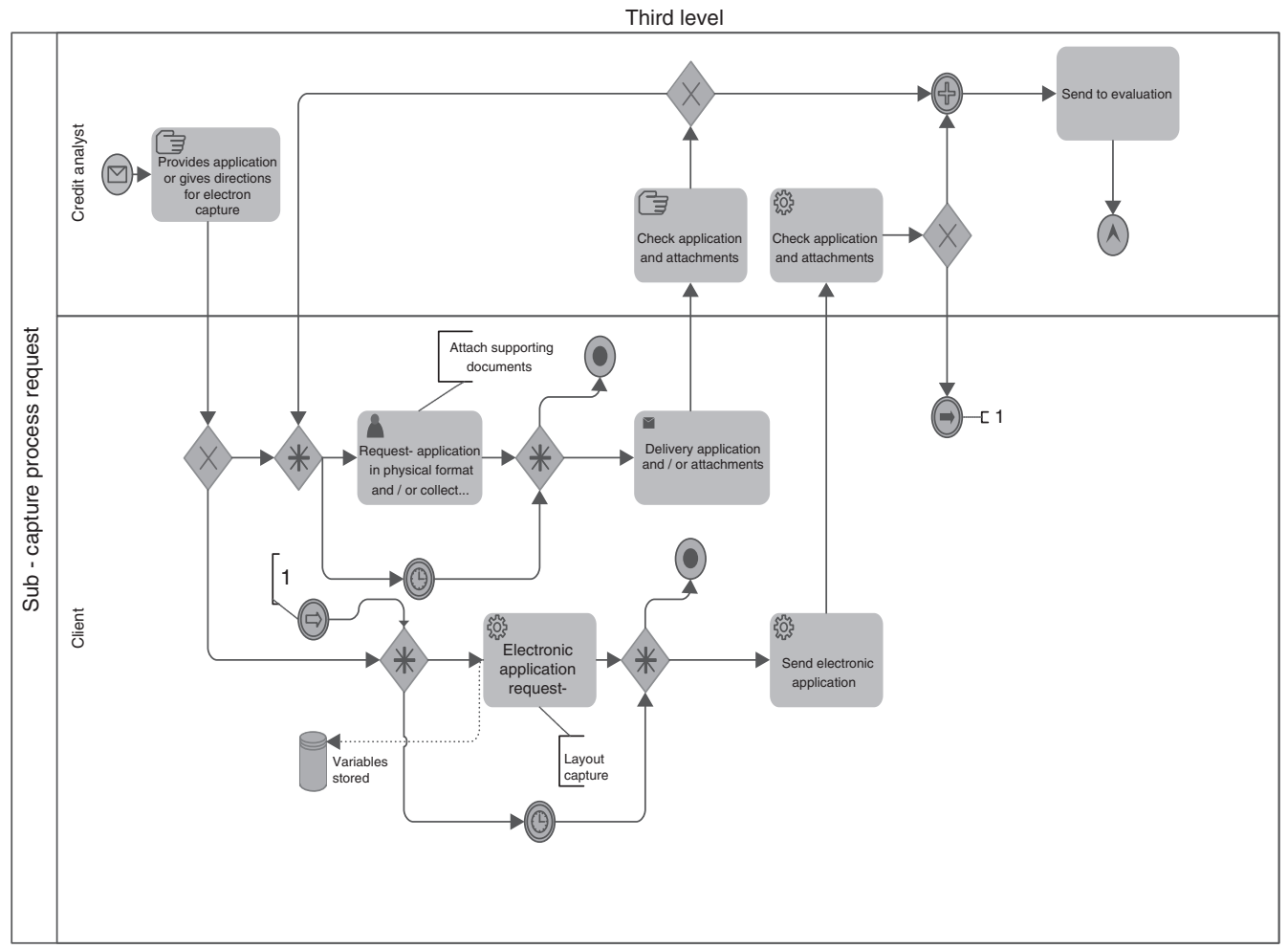

Fig. 4. (Continued).

The following section describes the initial resources of the project. They calculated by reference to the man-hour cost of similar projects in the phases of design, development, implementation, training and administrative costs.

\section{Initial project resources}

See Tables 2 and 3.

Table 2

Summary of initial resources required.

\begin{tabular}{llr}
\hline Resource type & Quantity & Total \\
\hline Human resources & 6 & $\$ 515,000.00$ \\
Investment costs & 21 & $\$ 79,000.00$ \\
Support & 4 & $\$ 140,000.00$ \\
Human resources for the operation & 3 & $\$ 114,000.00$ \\
& Total & $\mathbf{\$ 8 4 8 , 0 0 0 . 0 0}$
\end{tabular}

Source: Own formulation. 
Table 3

Detail of initial resources required.

\begin{tabular}{|c|c|c|c|c|}
\hline Concept & Description & Unitary cost & Quantity & Total \\
\hline Analyst & Master in finance or science & $\$ 50,000.00$ & 1 & $\$ 50,000.00$ \\
\hline Programmer Sr & $\begin{array}{l}\text { Bachelors or masters in } \\
\text { computer science }\end{array}$ & $\$ 100,000.00$ & 2 & $\$ 200,000.00$ \\
\hline Technical leader & Master or PhD in Science & $\$ 120,000.00$ & 1 & $\$ 120,000.00$ \\
\hline Project leader & Doctor of Science & $\$ 120,000.00$ & 1 & $\$ 120,000.00$ \\
\hline Design & WEB Designer & $\$ 25,000.00$ & $\begin{array}{l}1 \\
\text { Total human } \\
\text { resources }\end{array}$ & $\begin{array}{r}\$ 25,000.00 \\
\$ \mathbf{5 1 5 , 0 0 0 . 0 0}\end{array}$ \\
\hline Seminars & Promotion of the project & $\$ 25,000.00$ & 1 & $\$ 25,000.00$ \\
\hline Travel expenses & Collection of information & $\$ 3000.00$ & $\begin{array}{l}18 \\
\text { Total human } \\
\text { resources }\end{array}$ & $\begin{array}{l}\$ 54,000.00 \\
\$ 79,000.00\end{array}$ \\
\hline Computer equipment & Laptop & $\$ 30,000.00$ & 3 & $\$ 90,000.00$ \\
\hline Statistical software & $\begin{array}{l}\text { Specialized software } \\
\text { licensing }\end{array}$ & $\$ 50,000.00$ & 1 & $\$ 50,000.00$ \\
\hline & & & Total support & $\$ 140,000.00$ \\
\hline Qualified (courses) & Instructors & $\$ 20,000.00$ & 1 & $\$ 20,000.00$ \\
\hline Qualified (diploma courses) & $\begin{array}{l}\text { Professionals with } \\
\text { postgraduate }\end{array}$ & $\$ 40,000.00$ & 1 & $\$ 40,000.00$ \\
\hline Unqualified & Administrative support & $\$ 54,000.00$ & $\begin{array}{l}1 \\
\text { Total human } \\
\text { resources } \\
\text { (operation) }\end{array}$ & $\begin{array}{r}\$ 54,000.00 \\
\$ 114,000.00\end{array}$ \\
\hline
\end{tabular}

Source: Own formulation.

\section{Project evaluation}

\section{Cost-efficiency analysis}

The service cost for the proposal implies for EACP expenditures only for the services requested, the credit rating decreases the probability to grant a loan to "bad" customers, which has more severe effects than if the credit is not given to people "fulfilled". Therefore, benefits will occur (decreased probability of lending to "default", decrease in response times and reduced operating costs) in the following activities of the process of granting credit in EACP:

1. In the current process credit applicants have to wait days or even weeks for loan approval. Credit analysts use their own judgment to evaluate applicants, but asymmetric information between borrowers and lenders is so acute in the credit market for small business, which biases are present in the credit analysis and discretion rather than a systematic risk assessment. Information asymmetries also inhibit competition in the market for loans to PYMEs.

2. Institutions also specialize in municipal credit banks, with low average credit and a comparable size, recorded operating costs equivalent to almost half of which are presented in the microfinance institutions (MFI) in the Mexican market. An explanation may be the differences in the productivity of analysts. Lack of training and high turnover of analysts, to the point that even the new entities, where the turnover is greater than $100 \%$ in one year. Lack of training and high turnover of analysts, to the point that even the new entities, where the turnover is 
higher than $100 \%$ in one year. Obviously, rotation and "piracy Analyst" between competitors is facilitated in markets with heavy competition, and where the risk assessment methodology does not require an assessment of the repayment capacity of debtors, but the ability to form groups of debtors.

3. The lack of scale and efficiency is in the center of the explanation of why high interest rates persist in the Mexican market. To this must be added the stimulus toward public funding oriented to microfinance institutions to carry out operations to rural areas of less than 50,000 inhabitants, which could be causing overspending in mostly weak and unsustainable institutions, to serve more risky, complex and costly rural markets.

\section{Cost-benefit analysis}

In order to determine the profitability of the project are used the criteria of net present value, internal rate of return and payback period of investment, the notes in this section are based basically on project evaluation guides (CEPEP, 2015). The following describes techniques for calculating.

The net present value (NPV) is the present value of all cash flows of the project (positive and negative) relevant evaluation. This method consists of determining equivalence, in the present, the future cash flows generated by a project and compare it with the initial outlay. NPV formula is as follows.

$$
\mathrm{NPV}=-\sum_{t=0}^{m} \frac{I_{t}}{(1+r)^{t}}+\sum_{t=1}^{t=n} \frac{B_{t}-C_{t}}{(1+r)^{t}}
$$

where $I=$ total investment, $B_{t}=$ total profits in period $t, C_{t}=$ total costs in the period $t, m=$ execution or construction period, $r=$ discount rate or opportunity cost of money, $n=$ number of years of evaluation horizon.

When analyzing an individual project, the decision criteria applicable to the NPV indicates that it is profitable if the present value of the stream of benefits is greater than the present value of the stream of costs. In other words, it should undertake a project if the NPV is positive.

The average fee (usually annual) period is obtained due to the project, known as internal rate of return (IRR). Technically it is defined as the discount rate that makes the NPV equal to zero.

The formula for calculating the IRR is:

$$
\mathrm{NPV}=I_{0}+\sum_{r=1}^{r=n} \frac{B_{t}-C_{t}}{(1+\mathrm{IRR})^{t}}=0
$$

where $l_{0}=$ investment in period zero, $B_{t}=$ total profits in period $t, C_{t}=$ total costs in the period $t$, $n=$ number of years of evaluation horizon.

When you are evaluating two or more independent investment and flows behave "normally", i.e. with a single cusp, it is appropriate to accept those investments with IRR $>r$.

The period payback (PP) is the time that the project must operate to recover the initial investment, considering the value of money over time. To obtain the present value of each project flows is calculated, taking a cumulative flow. At the moment it is zero, the investment has been recovered; the period in which this happens will be the PP.

Thus the net present value of the project including risk analysis and sensitivity is calculated using the Monte Carlo method. The variable Assessment Services (measures the expected revenues from services) is calculated, first Pert probability distribution is used to calculate the fee assessment 


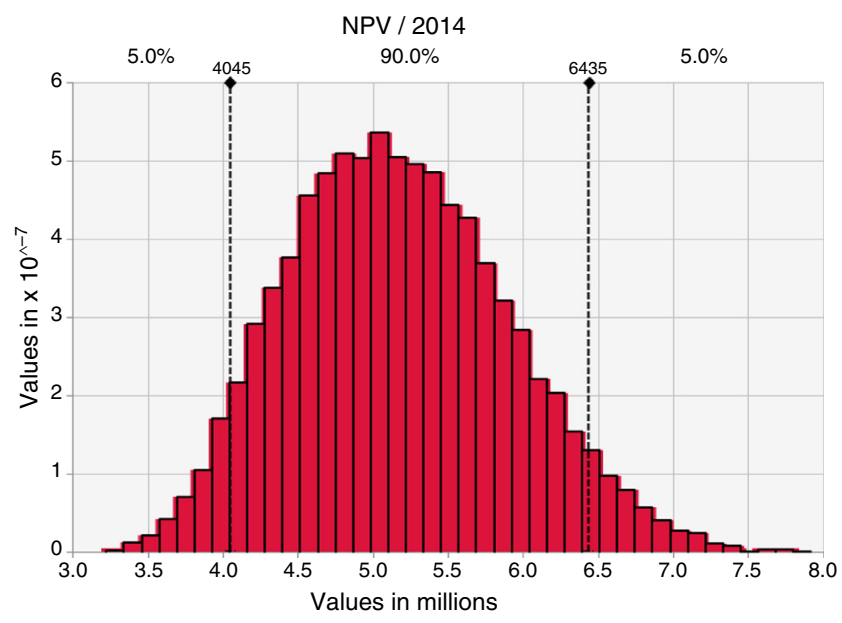

Fig. 5. Monte Carlo simulation for NPV. Source: Own formulation.

services and to estimate the average requests, and second Triangular distribution ${ }^{10}$ is used to approximate the percentage of market share. After running 10,000 simulations to calculate the NPV by using the software @ Risk, ${ }^{11}$ the results are shown in Fig. 5. For any case the NPV is positive, so the project is profitable for a discount rate of $25 \%$, internal rate of return of $157 \%$ and period payback of two years.

In Table 4, the results of the financial projections are presented considering that would serve $10 \%$ of the demand for such services, in a horizon of 5 years and the discount rate is $25 \%$, the detail of unit costs and service fees are omitted because the project is in process of evaluation and implementation and provide this information would jeopardize its viability.

According to the results of the screening, the project is financially feasible as it has a positive present value for any case, a high rate of return and payback period on investment within the first two years.

The above is based on the fact that for the implementation and operation resources required are minimal, once developed and implemented the technology platform and applications, evaluation service of credit applications is provided automatically without intervention of the personnel responsible for the custody and operation of the platform.

However it is a feasible project in terms of cost-benefit from the approach of savings institutions and popular and profitable credit as an investment project for the service provider, as shown in this and the previous section, it should deepen the analysis of risk factors and barriers to entry for this type of initiative.

To have an integral analysis of project risks is required to make a diagnosis on the current operation of the EACP, through a survey of a representative sample that includes at least 9 credit institutions that grant credit facilities to the popular sector, 3 of the northern region, 3 of the central region and 3 in the southern region. With this information we would be able to define a scheme

\footnotetext{
${ }_{10}$ According to the Project Management Institute, http://www.pmi.org, probability distributions pert and triangular are used in the risk management of investment projects.

11 The simulation results are available via e-mail request.
} 
Table 4

Financial projection.

\begin{tabular}{|c|c|c|c|c|c|c|}
\hline Concept & 2014 & 2015 & 2016 & 2017 & 2018 & 2019 \\
\hline \multicolumn{7}{|l|}{ Sales } \\
\hline Assessment services & & 421,003 & 855,071 & $1,402,601$ & $1,877,801$ & $2,474,289$ \\
\hline Consulting and support & & 84,201 & 171,014 & 561,040 & 751,120 & 989,716 \\
\hline Training & & 42,100 & 85,507 & 280,520 & 375,560 & 494,858 \\
\hline Graduates & & 40,000 & 75,000 & 100,000 & 150,000 & 200,000 \\
\hline Market share & & $2 \%$ & $4 \%$ & $6 \%$ & $8 \%$ & $10 \%$ \\
\hline $\begin{array}{l}\text { Percentage of advice with } \\
\text { respect to total services }\end{array}$ & & $20 \%$ & $20 \%$ & $40 \%$ & $40 \%$ & $40 \%$ \\
\hline $\begin{array}{l}\text { Percentage of courses with } \\
\text { respect to total services }\end{array}$ & & $50 \%$ & $50 \%$ & $50 \%$ & $50 \%$ & $50 \%$ \\
\hline Participants graduate & & 8 & 15 & 20 & 30 & 40 \\
\hline Cash inflows & 0 & 587,304 & $1,186,593$ & $2,344,161$ & $3,154,482$ & $4,158,862$ \\
\hline \multicolumn{7}{|l|}{ Initial investment } \\
\hline Seminars & 25,000 & 25,000 & 25,000 & & & \\
\hline Travel expenses & 50,000 & 50,000 & 50,000 & 50,000 & 50,000 & 50,000 \\
\hline Technical support (design) & 12,250 & & & & & \\
\hline \multicolumn{7}{|l|}{ Computer equipment } \\
\hline Laptop & 90,000 & & & & & \\
\hline Software & 50,000 & & & & & \\
\hline \multicolumn{7}{|l|}{ Skilled labor } \\
\hline Programmers & 210,000 & 52,500 & & 52,500 & & 52,500 \\
\hline Analyst & 50,000 & 25,000 & 25,000 & 25,000 & 25,000 & 25,000 \\
\hline Technical leader & 120,000 & & & & & \\
\hline Manager project & 120,000 & & & & & \\
\hline \multicolumn{7}{|l|}{ Labor operation } \\
\hline Training & & 20,000 & 20,000 & 20,000 & 20,000 & 20,000 \\
\hline Graduates & & 40,000 & 40,000 & 40,000 & 40,000 & 40,000 \\
\hline Not skills & & 54,000 & 54,000 & 54,000 & 54,000 & 54,000 \\
\hline Office & & & 1500 & 1500 & 1500 & 1500 \\
\hline Cash outflows & 727,250 & 266,500 & 215,500 & 243,000 & 190,500 & 243,000 \\
\hline Net cash & $-727,250$ & 320,804 & 971,093 & $2,101,161$ & $2,963,982$ & $3,915,862$ \\
\hline
\end{tabular}

Source: Own formulation.

of risk depending on the expected profit and profitability, therefore is proposed for the following researches a risk analysis to have sufficient elements for successful project management.

\section{Conclusions}

A credit scoring system with the characteristics proposed in this paper promotes efficiency during the different phases and activities of lending, understanding the efficiency in terms of reduced operating costs, decrease in response times and overall decrease the probability of granting "bad" loans. This generates information available at any time for making decisions with a solid statistical basis, as well as standardize the assessment processes which will eventually impact the micro-credit market in lowering interest rates.

From the point of view of the financial services provider, it is a profitable project according to the calculations of net present value, internal rate of return and payback period of investment.

Collaterally, with the information that enters in the evaluation system and prior agreement between the institutions of savings and loan, it is possible to lay the groundwork to form a basis of 
initial data for a credit information system for this sector, which will help tremendously to reduce asymmetric information in the credit market characteristic of the micro-finance.

\section{References}

Al Amari, A. (2002). The credit evaluation process and the role of credit scoring: A case study of Qatar (Ph.D. thesis). University College Dublin.

AMSOFIPO. (n.d.). http://www.amsofipo.mx/.

Anderson, R. (2007). The credit scoring toolkit: Theory and practice for retail credit risk management and decision automation. New York: Oxford University Press.

BID. (2011). Microfinanzas en América Latina y el Caribe: El sector en cifras. D.F.: Banco Interamericano de Desarrollo.

CEPEP. (2015). Center of Studies for the Preparation and Socioeconomic Assessment Projects. Retrieved from http://www.cepep.gob.mx/work/models/CEPEP/metodologias/documentos/Guia_General_FINAL.pdf

Chandler, G., \& Coffman, J. (1979). A comparative analysis of empirical vs judgmental credit evaluation. Journal of Retail Banking, 1(2), 12-26.

CNBV. (2001). Ley de Ahorro y Crédito Popular. Méxido D.F.: CNVB.

Consultative Group to Assist the Poor. (2015). CGAP. Retrieved from CGAP: http://www.cgap.org/.

Crook, J. (1996). Credit scoring: An overview. Working paper series no. 96/13. British Association, Festival of Science, University of Birmingham, The University of Edinburgh.

Hand, D. J., \& Henley, W. E. (1997). Statistical classification methods in costumer credit scoring: A review. Journal of the Royal Statistical Association, 160, 523-542.

Hand, D. J., \& Jacka, S. D. (1998). Statistics in finance. Arnold Applications of Statistics, 106.

Hussain, I. (2014). Cloud client/server model systems. Kindle.

Hussein, P. (2011). Credit scoring, statistical techniques and evaluation criteria: A review of literature. Intelligent Systems in Accounting, Finance and Management, 18(2-3), 59-88.

Institute, P. M. (2004). PMBok. PMI.

Pagos, B. I. (2004). BASILEA II. BIS.

Rayo, S., \& Lara, J. (2010). Un modelo de Credit Scoring para instituciones de microfinanzas en el marco de Basilea II. pp. 37.

Wegner, P. (1996). Interoperability. ACM Computing Survey, 28, 285-287. 